\title{
Genetic diversity of Plasmodium vivax revealed by the merozoite surface protein-1 icb5-6 fragment
}

\author{
Wei Ruan', Ling-ling Zhang ${ }^{1}$, Yan Feng ${ }^{1}$, Xuan Zhang ${ }^{1}$, Hua-liang Chen', Qiao-yi Lu', Li-nong Yao ${ }^{1 *}$ and Wei Hu²
}

\begin{abstract}
Background: Plasmodium vivax remains a potential cause of morbidity and mortality for people living in its endemic areas. Understanding the genetic diversity of $P$. vivax from different regions is valuable for studying population dynamics and tracing the origins of parasites. The PVMSP-1 gene is highly polymorphic and has been used as a marker in many $P$. vivax population studies. The aim of this study was to investigate the genetic diversity of the PVMSP-1 gene icb5-6 fragment and to provide more genetic polymorphism data for further studies on $P$. vivax population structure and tracking of the origin of clinical cases.

Methods: Nested PCR and sequencing of the PVMSP-1 icb5-6 marker were performed to obtain the nucleotide sequences of 95 P. vivax isolates collected from Zhejiang province, China. To investigate the genetic diversity of PVMSP-1, the 95 nucleotide sequences of the PVMSP-1 icb5-6 fragment were genotyped and analyzed using DnaSP v5, MEGA software.
\end{abstract}

Results: The 95 P. vivax isolates collected from Zhejiang province were either indigenous cases or imported cases from different regions around the world. A total of 95 sequences ranging from 390 to $460 \mathrm{bp}$ were obtained. The 95 sequences were genotyped into four allele-types (Sal I, Belem, R-III and R-IV) and 17 unique haplotypes. R-III and Sal I were the predominant allele-types. The haplotype diversity $(\mathrm{Hd})$ and nucleotide diversity (Pi) were estimated to be 0.729 and 0.062, indicating that the PVMSP-1 icb5-6 fragment had the highest level of polymorphism due to frequent recombination processes and single nucleotide polymorphism. The values of $\mathrm{dN} / \mathrm{dS}$ and Tajima's D both suggested neutral selection for the PVMSP-1icb5-6 fragment. In addition, a rare recombinant style of R-IV type was identified.

Conclusions: This study presented high genetic diversity in the PVMSP-1 marker among $P$. vivax strains from around the world. The genetic data is valuable for expanding the polymorphism information on $P$. vivax, which could be helpful for further study on population dynamics and tracking the origin of $P$. vivax.

Keywords: Plasmodium vivax, PVMSP-1, Genetic diversity, Malaria

\section{Multilingual abstracts}

Please see Additional file 1 for translations of the abstract into the five official working languages of the United Nations.

\section{Background}

Malaria remains a severe public health problem worldwide, with more than 200 million cases causing 600 000-800 000

\footnotetext{
*Correspondence: Inyao@cdc.zj.cn; huwwyz@163.com

'Department of Communicable Diseases of Control and Prevention, Zhejiang

Provincial Centre for Disease Control and Prevention, Hangzhou, China

${ }^{2}$ School of Life Sciences, FuDan University, Shanghai, China
}

deaths annually [1]. About $9 \%$ of these cases are caused by the parasite Plasmodium vivax [1]. Although malaria induced by $P$. falciparum accounts for more deaths, $P$. vivax has a wider geographical distribution and a dormant liver stage which can easily lead to relapse.

Understanding the genetic diversity of malaria parasites from different regions is important for studies on population dynamics and is also valuable in discriminating parasite clones from infected individuals and tracing the origin of parasites [2, 3]. Currently, several genetic markers have been used to study $P$. vivax populations'genetic diversity [4-7], the most popular being $P$. vivax merozoite surface 
protein 1 (PvMSP-1). $P v M S P-1$ is an important protein for erythrocyte invasion, and thus vaccine research, which is encoded by the $P v M S P-1$ gene with approximately 1 720 amino acids. $P v M S P-1$ is composed of conserved, partially conserved and variable regions. It has been shown in several studies that the $P v M S P-1$ gene exhibits a mosaictype structure due to recombination events [8-10]. As a partial fragment of the variable region in the $P v M S P-1$ gene, the inter-species conserved fragments 5 (icb5) and icb6 show high polymorphisms from insertions, deletions, intra-allelic recombination and point mutations [4, 9-13]. The fragment consists of three pairs of dimorphic gene elements marked as I/II, P/Q and R/S, respectively. So far, four recombination types have been identified as Belem (I/Q/S), Salvador (Sal I, II/P/R)), recombination III (R-III, II/Q/S) and IV (R-IV, II/P/S) $[8,14,15]$. Compared to Sal I, Belem type contains a distinctive structure with a different length of Glutamine $(\mathrm{Q})$ repeats. R-III and R-IV were the newly generated types through the recombination of Sal I and Belem. Since there is extensive genetic polymorphism of the PvMSP-1 icb5-6 fragment, it is suitable for molecular discrimination of relapse episodes $[8,16]$, phylogenetic studies and genetic traceability studies $[2,17]$.

Most studies investigating the genetic diversity of $P$. vivax have focused on samples in a particular geographic region $[6,7,12,18]$. Only a few studies were implemented to compare samples from different regions. In this study, P. vivax malaria samples from infections in different countries/regions (including Africa, South Asia, Southeast Asia, West Asia and partial regions of China) were collected in the Zhejiang province, aiming to investigate the genetic diversity of the $P v M S P-1$ gene icb5-6 fragment and provide more genetic polymorphism data for further study on population structure and for tracking the origin of clinical cases.

\section{Materials and methods Sample collection}

Blood samples were collected from indigenous and imported symptomatic $P$. vivax malaria patients in Zhejiang Province, China, from 2006 to 2013. The inclusion criteria were patients infected with $P$. vivax who were diagnosed definitely via microscopic examination and nested PCR. The microscopic examinations were done following the procedures of the WHO outlined in basic malaria microscopy [19], and the Nested PCR (NP) was implemented following the NP 1993 procedures [20]. All patients confirmed to have the $P$. vivax infection received normative anti-malarial drug treatment. An individual case survey was also conducted to find out whether they had a history of malaria and a travel history abroad. After informed consent from adults or legal guardians of children, $2.0 \mathrm{ml}$ whole blood samples were collected in an anticoagulant tube and stored at $-20{ }^{\circ} \mathrm{C}$ until DNA extraction was carried out.
DNA extraction and species identification for Plasmodium The total DNA was extracted from $200 \mu \mathrm{l}$ of the whole blood using a QIAamp DNA Blood Mini Kit (QIAGEN, Germany), following the manufacturer's instructions. DNA was eluted in $200 \mu \mathrm{l}$ of Tris-EDTA buffer and kept at $4{ }^{\circ} \mathrm{C}$ until use, or stored at $-20{ }^{\circ} \mathrm{C}$. A standard nested PCR amplification method was used to identify Plasmodium species following previously reported protocols [20, 21]. The primers for nested PCR detection of Plasmodium spp. were listed in Additional file 2: Table S1. All amplification reactions were carried out in a total volume of $20 \mu \mathrm{l}$, containing 6.8 or $7.8 \mu \mathrm{l}$ of $\mathrm{dd}_{2} \mathrm{O}, 0.6 \mu \mathrm{l}$ of each primer $(10 \mu \mathrm{M}$ ), and $10 \mu \mathrm{l}$ Green Master Mix (Promega, USA). Primary amplification reactions were initiated with the addition of $2.0 \mu \mathrm{l}$ template genomic DNA prepared from the blood samples, and $1.0 \mu \mathrm{l}$ of the primary reaction amplification was used as a template in the secondary amplification reactions. The amplified PCR products were visualized in $1.5 \%$ agarose gel containing $5 \mu \mathrm{l} / 100 \mathrm{ml}$ GelRed Nucleic Acid Gel Stain (Biotium, USA).

\section{Amplification and sequencing of the PvMSP-1 icb5-6 gene fragment}

The DNA fragment of PvMSP-1 icb5-6 was amplified by nested PCR following previously reported protocols [22]. The primers for nested PCR detection of PvMSP-1 icb56 were listed in Additional file 2: Table S2. In brief, the primary PCR was performed in a total volume of $20 \mu \mathrm{l}$ containing $2 \mu \mathrm{l}$ DNA template, $10 \mu \mathrm{l}$ PCR Green Master Mix (Promega, USA), $1 \mu \mathrm{l}$ of each primer $(10 \mu \mathrm{M})$, and $6 \mu \mathrm{lddH_{2 }}$ O. The secondary PCR was performed in a total volume of $50 \mu \mathrm{l}$ containing $2 \mu \mathrm{l}$ DNA template, $25 \mu \mathrm{l} \mathrm{PCR}$ Green Master Mix (Promega, USA), $2 \mu \mathrm{l}$ of each primer

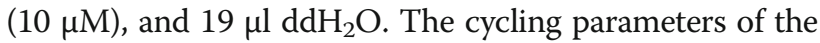
primary and secondary PCR were as follows: initial denaturation at $94{ }^{\circ} \mathrm{C}$ for $5 \mathrm{~min}$, followed by 30 cycles of $94^{\circ}$ $\mathrm{C}$ for $1 \mathrm{~min}, 55^{\circ} \mathrm{C}$ for $1 \mathrm{~min}$, and $72^{\circ} \mathrm{C}$ for $1 \mathrm{~min}$, with a final extension of $72{ }^{\circ} \mathrm{C}$ for $5 \mathrm{~min}$. The PCR products were visualized in $1.5 \%$ agarose gel electrophoresis containing $5 \mu \mathrm{l} / 100 \mathrm{ml}$ GelRed Nucleic Acid Gel Stain (Biotium, USA). Positive PCR products were purified and directly sequenced in both directions using an ABI PRISM3730 DNA sequencer by Sangon Biotech (Shanghai, China).

\section{Data analysis}

Nucleotide and amino acid sequences were aligned using MEGA version 6 with the following published sequences of Sal I (accession no. AF435602) and Belem (accession no. M60807) [23]. The PvMSP-1 allele-types of P. vivax isolates were confirmed based on the alignment results. To find out the genetic diversity of the PvMSP-1 icb5-6 fragment, some indices were determined using the DnaSP version 5, including the number and frequency of haplotypes, haplotype diversity ( $\mathrm{Hd})$, and the nucleotide 
diversity $(\pi)$. In addition, the ratio of non-synonymous $(\mathrm{dN})$ to synonymous $(\mathrm{dS})$ substitution $(\mathrm{dN} / \mathrm{dS})$ was also calculated using DnaSP version 5 [24]. Additionally, to evaluate the neutral theory, Tajima's D test was carried out through DnaSP version 5 [24]. In order to elucidate the genetic relationships among the isolates, the phylogenetic tree was constructed using the neighbor-joining method implemented by MEGA version 6 .

\section{Results}

\section{Sample distribution}

In this study, 95 P. vivax samples were collected from Zhejiang province in Eastern China during 2006-2013. The $P$. vivax cases were mostly indigenous or imported from adjacent provinces during 2006-2011, while imported P. vivax cases from Southeast Asia, South Asia, etc. were dominant after 2012. From the 95 samples, sixty-nine showed a clear infection origin in the following areas: 2 in Africa (Ethiopia), 2 in Central China (Henan Province), 1 in Southwestern China (Yunnan Province), 39 in Eastern China (1 from Jiangsu Province, 30 from Anhui Province, 1 from Jiangxi Province, and 7 from Zhejiang Province), 6 in South Asia (India), 17 in Southeast Asia (6 from Myanmar, 1 from Indonesia, 8 from Cambodia, and 2 from Laos), and 2 in West Asia (Afghanistan).

\section{Allelic-type of PvMSP-1 icb5-6 fragment}

In this study, the PvMSP-1 icb5-6 fragment was successfully amplified from the total parasitic DNA obtained from a single $P$. vivax infection. A total of 95 sequences ranging to 390 to 460 bp were obtained and aligned with the Sal I and Belem reference sequences. Based on three dimorphic elements, the 95 sequences were divided into four allele-types: Sal I (37, 38.94\%), Belem (6, 6.32\%), RIII $(49,51.58 \%)$ and R-IV (3, 3.36\%). R-III and Sal I were the dominant allele-types. Sal I was mainly distributed in Southeast Asia, Africa, Eastern China, and South Asia. R-III was distributed in Southeast Asia, Eastern China, Central China, and West Asia. Belem was mainly distributed in Africa, South Asia, Southeast Asia, and Southwestern China, while R-IV was only found in Southeast Asia. The detailed distribution of the four allele-types is listed in Table 1.
The alignment of the 95 amino acid sequences revealed that Belem and R-III types have the structure of poly-Q, with the number of $\mathrm{Q}$ repeats ranging from 10 to 23. The poly-Q of Belem type mostly repeated more than 16 times, while it repeated mostly 10 times in R-III type, followed by 19 times, 18 times, 13 times and 23 times.

\section{Genetic diversity of the PvMSP-1 icb5-6 fragment}

During the alignment analysis, some gene gaps or missing data were found in partial sequences because of the differences in sequence length; therefore, only 330 bp gene sites were analyzed using DnaSP, and 65 SNPs (2 singleton variable sites and 63 parsimony informative sites) were found. As shown in Table 2, seventeen unique haplotypes were identified due to the occurrence of SNPs, with 12 haplotypes for Sal I, 2 haplotypes for Belem, 1 haplotype for R-III, and 2 haplotypes for R-IV. The haplotype diversity (Hd) and nucleotide diversity $(\mathrm{Pi})$ were estimated to be 0.729 and 0.062 , respectively. The analysis of synonymous and non-synonymous substitutions was performed for 106 codons of $P v M S P-1$ icb5-6 fragments. The ratio of non-synonymous substitutions $(\mathrm{dN})$ and synonymous substitutions (dS) were estimated to be 0.070 and 0.071 , respectively. The $\mathrm{dN} / \mathrm{dS}$ value was 0.986 , which indicated that the majority of the polymorphic sites are changing under neutral selection. Tajima's D test was also performed and estimated to be $1.873(P>0.05)$, which indicates neutral selection for the $P v M S P-1$ protein.

A typical sequence of 17 haplotypes was randomly selected for PvMSP-1icb5-6 amino acids sequence polymorphisms analysis. Forty-four amino acids polymorphism sites are shown in Fig. 1. Hap_1 and Hap_19 were the reference sequences for the Sal I and Belem, respectively. Seven non-synonymous changes at codon T792I, A795T, P796S, V809A, V818A, A823T, and Q831E were detected in the 12 haplotypes for Sal I type. There were no nonsynonymous changes among the two haplotypes for Belem type (Hap_12 and Hap_13) and Hap_19. Hap_10 was the only haplotype for R-III in which the polymorphism sites were Sal I-like in the element of I/II and Belem-like in the elements of P/Q and R/S. Hap_5 and Hap_9 were the

Table 1 Geographical distribution of 95 PVMSP-1 icb5-6 sequences based on allele-type level

\begin{tabular}{|c|c|c|c|c|c|c|c|c|c|}
\hline \multirow[t]{2}{*}{ Allele-type } & \multicolumn{8}{|c|}{ Infection origin } & \multirow[t]{2}{*}{ Total } \\
\hline & Africa & Central China & Eastern China & South Asia & Southeast Asia & Southwestern China & West Asia & Unknown & \\
\hline Belem & 1 & 0 & 0 & 2 & 1 & 1 & 0 & 1 & 6 \\
\hline $\mathrm{R}-\| \mid$ & 0 & 2 & 26 & 0 & 7 & 0 & 2 & 12 & 49 \\
\hline R-IV & 0 & 0 & 0 & 0 & 2 & 0 & 0 & 1 & 3 \\
\hline Sal I & 1 & 0 & 13 & 4 & 7 & 0 & 0 & 12 & 37 \\
\hline Total & 2 & 2 & 39 & 6 & 17 & 1 & 2 & 26 & 95 \\
\hline
\end{tabular}


Table 2 The allelic-type and frequencies of nineteen haplotypes

\begin{tabular}{llllll}
\hline Haplotype & Isolates No. & Allelic-type & Haplotype & Isolates no. & Allellic-type \\
\hline Hap_1* & 1 & Sal I & Hap_11 & 5 & Sal I \\
Hap_2 & 2 & Sal I & Hap_12 & 4 & Belem \\
Hap_3 & 1 & Sal I & Hap_13 & 2 & Belem \\
Hap_4 & 8 & Sal I & Hap_14 & 3 & Sal I \\
Hap_5 & 2 & R-IV & Hap_15 & 1 & Sal I \\
Hap_6 & 8 & Sal I & Hap_16 & 1 & Sal I \\
Hap_7 & 4 & Sal I & Hap_17 & 2 & Sal I \\
Hap_8 & 1 & Sal I & Hap_18 & 1 & Belem \\
Hap_9 & 1 & R-IV & Hap_19* & 1 & - \\
Hap_10 & 49 & R-III & - & - & - \\
\hline
\end{tabular}

*:The asterisk represent the reference sequences Sal I (AF435602) and Belem (M60807)

haplotypes for R-IV in which the polymorphism sites were Sal I-like in the elements of I/II and P/Q and Belem-like in the element of $\mathrm{R} / \mathrm{S}$. However, the amino acids at codon 782-784, 787, 791/818, and 823 of Hap_9 were AGGAT/ $\mathrm{VT}$ in the R/S element, which was the same as Sal I but not the same as Belem. The polymorphism between Hap_5 and Hap_9 indicated that the recombinant sites between $\mathrm{P} / \mathrm{Q}$ and $\mathrm{R} / \mathrm{S}$ elements were different. The two putative recombinant sites were marked in Fig. 2. As shown in the figure, in the region of $\mathrm{P} / \mathrm{Q}$ and $\mathrm{R} / \mathrm{S}$ elements, the sequences of Sal I and Belem were separated into the four regions of $\mathrm{S} 1, \mathrm{~S} 2, \mathrm{C}$, and $\mathrm{S} 3$, and $\mathrm{B} 1, \mathrm{~B} 2, \mathrm{C}$, and $\mathrm{B} 3$, respectively; $\mathrm{C}$ was the conservative region. The recombinant site normally located between S1 and B2, and Hap_5 was generated with the structure of $\mathrm{S} 1, \mathrm{~B} 2, \mathrm{C}$, and B3. However, Hap_9 was generated with the structure of S1,
$\mathrm{S} 2, \mathrm{C}$, and $\mathrm{B} 3$, due to the putative recombinant site located in the $\mathrm{C}$ region.

\section{Sequence polymorphism and clustering of PvMSP-1}

Among the four allele-types, Sal I showed more diversity than the other three types. A dendrogram of $P v M S P-1$ icb5-6 sequences was constructed using 37 nucleotide sequences from Sal I type. This analysis grouped the 37 isolates into multi-subtypes with the corresponding haplotype (Fig. 3). The dendrogram showed some significant relationships between subtype and infection source, such as the five subtypes (Hap_4, 7, 11, 2, 6) in Eastern China, two subtypes (Hap_4, 18) in India, and the subtype (Hap_14) which was unique to Myanmar. Using the sequence polymorphisms of $P v M S P-1$ icb5-6 amino acids shown in Fig. 1, the relationship between

\section{I/II \\ $\mathbf{P} / \mathbf{Q}$ $\mathbf{R} / \mathbf{S}$

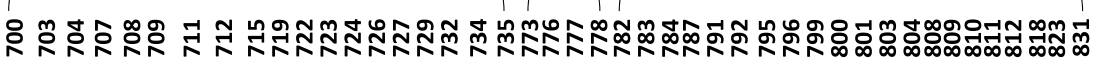 Hap_1 N T V A D I A K S AT G T G V Q A V A QTAGGAT T AP T QAPEAVPS VA Q Hap_2 $N T V$ A D I A K S ATGTGNVQ AVAQQTAGGAT I APT QAPEAVPPS T Q Hap_3 N T V A D I A K S ATGTGNVQ AVAQQTAGGATI AST QAPEAAPPS VTQ Hap_4 N T V A D I A K S AT GT GNVQ AVAQQTAGGATT APT QAPEAVPPS T Q Hap_5 N T V A D I A K S ATGTGNVQ AVAQQTDAQI PTS A - GVAT- - - A AE Hap_6 N T V A D I A K S ATGTGNVQAVAQQTAGGATIAPT QAPEAAPPS VTQ Hap_7 N T V A D I A K S ATGT GNVQ AVAQQTAGGATTTPT QAPEAVPPS T Q Hap_8 N T V A D I A K S A T G T N V Q A V AQQTAGGATTAPT QAPEAVPPS VAE Hap_9 N T V A D I A K S ATGT GNVQ AVAQQTAGGATTS A - GVAT- . - VTE Hap_10 N T V A D I A K S ATGT GNVQ AVS V P ADA QI P T S A - GVAT- - - A AE Hap_11 N T V A D I A K S ATGT GNVQ AVAQQTAGGATT APT QAPEA APS V Q Hap_12 A - S A P T S L S - A AEVTV SESVPADAQI PTS A - GVAT- - - AAE Hap 13 A - S A P T S L S - AAEVTV SES VPADAQIPT S A - GVAT- - - AAE Hap_14 N T V A D I A K S AT G T G V Q A A Q QTAGGATI APT QAPEAAPPS V E Hap_15 N T V A D I E K S A T G T G N V Q A V A Q QTAG G T I A P T QAPEA APPS T Q Hap_16 N T V A D I A K S AT T GNVQAVAQQTAGGATTAPT QAPEAAPPSAAE Hap_17 N T V A D I A K S ATGT GNVQ A V A Q Q A G G T T A P T QAPEAAPPS VTE Hap_18 N T V A D I A K S ATGT GNVQ AVAQQTAGGATT AST QAPEAVPPS T Q Hap_19 A - S A P T S L S - A AEVTV SES VPADAQI P T S A - GVAT- - - AAE}

Fig. 1 Sequence polymorphisms of PVMSP-1 icb5-6 amino acids identical to those of the reference strain, Sal I (AF435602, protein_id: AAN86215.1). Amino acids identical to those of the reference strain are marked in black typeface, the substituted amino acids are marked in red and blue typeface 


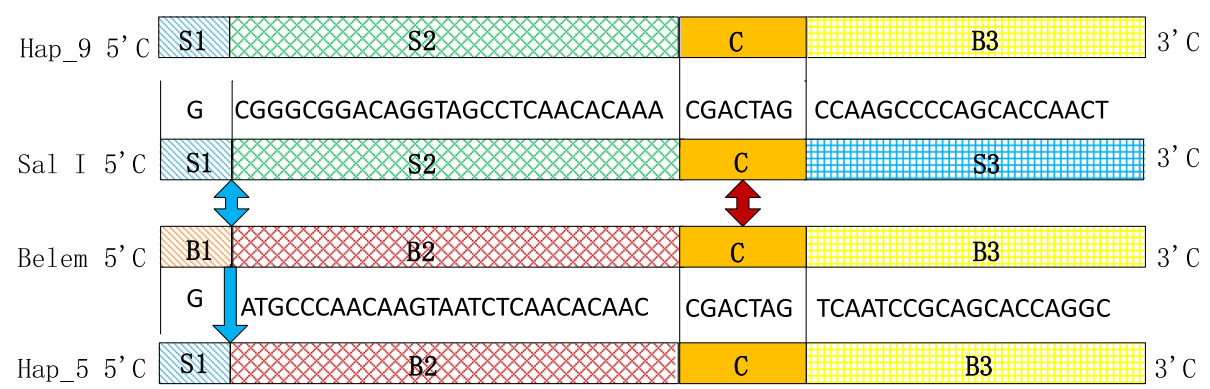

Fig. 2 The putative recombinant sites between $P / Q$ and R/S elements of Hap_5 and Hap_9. (Blue arrow: recombinant site of Hap_5; Red arrow: recombinant site of Hap_9)

amino acid sequence polymorphisms and their origin has been summarized for P. vivax tracking (Fig. 4). For example, according to the barcode and dendrogram, the isolates coding 173 and 105 were predicted to come from Eastern China, while the sample coding 671 may have come from Myanmar. The dendrogram of PvMSP1 icb5- 6 sequences was also constructed using 6 nucleotide sequences from Belem type and 3 nucleotide sequences from R-IV type (Fig. 5). Belem and R-IV were both grouped into two haplotypes, which were less diverse than Sal I type. Forty-nine isolates of R-III were grouped into one haplotype- it was highly conservative for the isolates from different regions.

\section{Discussion}

The malarial parasite $P$. vivax was eradicated in many subtropical countries and significantly reduced in some tropical regions through the application of vector control measures and the deployment of mass treatment of febrile individuals. Unfortunately, climate change, socioeconomic change and human population movements have contributed to the re-emergence of the infection in some malaria-free areas. Therefore, $P$. vivax remains a potential cause of morbidity and mortality for the people living in endemic areas. In malaria hypo-endemic regions, different parasite genotypes are circulating and geographic isolation may exist [5]. Additionally, P. vivax populations and transmission patterns are also changing constantly with increasing movement of human populations [25].

To better understand $P$. vivax populations and transmission dynamics, the genetic diversity of $P$. vivax was investigated using the genetic marker PvMSP-1. In this study, $95 P$. vivax isolates were collected from the Zhejiang province of Eastern China during 2006-2013. Zhejiang province was once a low epidemic area of vivax malaria. The last local malaria case was reported in 2011. Although Zhejiang province promised to achieve the goal of eliminating malaria by 2016, malaria importation remains a serious challenge because a vector
(Anopheles sinensis) still exists, and with imported cases could cause a resurgence in susceptible areas.

The $P v M S P-1$ gene exhibits high genetic variation and complex structuring in a number of geographic regions around the world [9]. It has been used as marker in many genetic studies of $P$. vivax $[4,12,26]$. Mutation and frequent recombination events are the main mechanisms responsible for the high genetic diversity observed in the P. vivax icb5-6 fragment [9]. Four allele-types, Belem, Sal I, and recombination types (R-III and R-IV), of the PvMSP-1 icb5-6 fragment have been described worldwide $[8,14]$. In the present study, the four alleletypes were identified from 95 P. vivax isolates. Because of quantitative limitations and geographic restriction of $P$. vivax sampling, this study was limited in its ability to describe the diversity of $P v M S P-1$ icb5-6 around the world. However, among the cases with a clear infection origin, over half of cases (56.5\%) were distributed in Eastern China, followed with $24.6 \%$ in Southeast Asia, 8.7\% in South Asia, 2.9\% in Central China, 2.9\% in Africa, 2.9\% in West Asia and 1.4\% in Southwestern China. R-III was the dominant type in Eastern China, followed by Sal I, while Belem and R-IV were absent in this region. This result was in concordance with previous reports in the Anhui province (the other province of Eastern China) [18]. It has been reported that the generation of R-types arise from intragenic recombination of Belem and Sal I types in mosquito vectors $[9,27]$. The dominance of R-III type with the absence of Belem type in Eastern China made the generation of the R-III type unusual, which could be related to sampling bias, population changes of mosquito species, or selection by host immunity pressure on specific types of parasite. In fact, studies conducted in Southern Mexico reported that the distribution of different $P$. vivax populations was largely determined by their infectivity of two species of anopheline vectors [28]. Hence, in Eastern China, the changes in mosquito strains may lead to changes in parasite population structure. The four allele-types were all detected in Southeast Asia, with Sal I and R-III being the dominant allele-types. The population structure of $P$. vivax in 


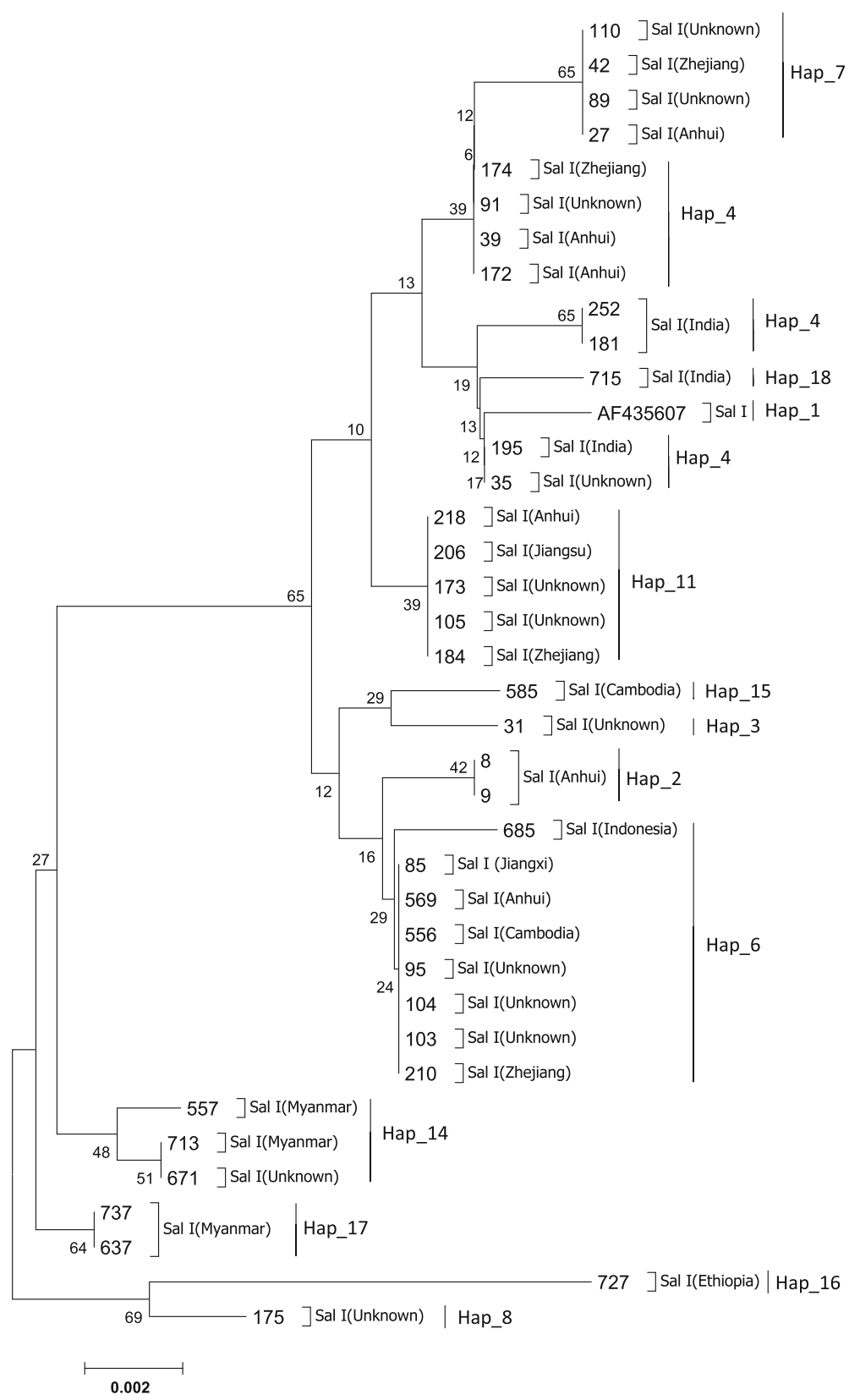

Fig. 3 Dendrogram of the PVMSP-1 icb5-6 based on the nucleotide sequences of 37 isolates of Sal I type and Sal I reference sequence (AF435602)

Southeast Asia was more diverse than in other regions. The high levels of recombinant types and Sal I in Southeast Asia are in concordance with the report from Myanmar [26]. Besides this, Southeast Asia was the only region where R-IV was detected. The Belem type was also observed in Southwestern China, and it can be speculated that this region may have a similar allele-type distribution to Southeast Asia, because it was located on the border between China and countries of Southeast Asia.

In the present study, the analysis of single-nucleotide polymorphisms revealed 63 parsimony informative sites and a total of 17 haplotypes were observed based on the SNPs. Values of $d N / d S$ and Tajima's $D$ both suggested neutral selection for the region of $P v M S P-1$ icb5-6, a result which differs compared to a study conducted in Southern Mexico, where the $\mathrm{dN} / \mathrm{dS}$ test indicated that different icb5-6 subfragments might be subjected to either positive or purifying selection [29]. This difference may have resulted from sampling bias or differences in analysis structure, as the analysis in the present study was based on the level of the entire icb5-6 fragment, while it was analyzed by each subfragment in the Mexican study. 


\begin{tabular}{|c|c|c|c|c|c|c|c|c|}
\hline Hap_1 & $\mathrm{T}$ & $A$ & $P$ & V & V & A & $\mathrm{Q}$ & Thailand \\
\hline Hap_2 & 1 & A & $P$ & V & V & $\mathrm{T}$ & Q & Eastern China \\
\hline Hap_3 & I & $A$ & S & $A$ & V & $\mathrm{T}$ & Q & Unknown \\
\hline Hap_4 & $\mathrm{T}$ & $A$ & $P$ & V & V & $\mathrm{T}$ & Q & Eastern China, India \\
\hline Hap_6 & 1 & $A$ & $P$ & $A$ & V & $\mathrm{T}$ & Q & $\begin{array}{l}\text { Eastern China, Cambodia } \\
\text { Indonesia }\end{array}$ \\
\hline Hap_7 & 1 & $\mathrm{~T}$ & $P$ & V & V & $\mathrm{T}$ & Q & Eastern China \\
\hline Hap_8 & $\mathrm{T}$ & $A$ & $P$ & V & V & A & $E$ & Unknown \\
\hline Hap_11 & $\mathrm{T}$ & $A$ & $P$ & $A$ & V & $\mathrm{T}$ & $\mathrm{Q}$ & Eastern China \\
\hline Hap_14 & 1 & $A$ & $P$ & $A$ & V & $\mathrm{T}$ & $E$ & Myanmar \\
\hline Hap_15 & 1 & $A$ & $P$ & $A$ & V & $\mathrm{T}$ & $\mathrm{Q}$ & Cambodia \\
\hline Hap_16 & $\mathrm{T}$ & $A$ & $P$ & $A$ & $A$ & $A$ & $E$ & Ethiopia \\
\hline Hap_17 & $\mathrm{T}$ & $A$ & $P$ & $A$ & $\mathrm{~V}$ & $\mathrm{~T}$ & $E$ & Myanmar \\
\hline Hap_18 & $\mathrm{T}$ & $A$ & $\mathrm{~S}$ & V & $\mathrm{V}$ & $\mathrm{T}$ & Q & India \\
\hline
\end{tabular}

Fig. 4 The molecular barcode for haplotypes of Sal I type. Hap_1 represent the Sal I reference strain (AF435602, protein_id: AAN86215.1)

In this study, Sal I type consisted of 12 haplotypes and it was more diverse than the other three allele-types. Based on the polymorphism sites, the relationship between amino acid sequence polymorphisms and case origin was summarized for the preliminary identification and tracking of $P$. vivax. R-IV was relatively rare and was only detected in Southeast Asia. It consisted of two haplotypes, Hap_5 and Hap_9. The amino acids of Hap_9 at codon $782-784,787,791 / 818$, and 823 were
AGGAT/VT, which were the same as Sal I, while those of Hap_5 were DAQIP/AA, which were the same as Belem. The recombinant site of Hap_5 was the most common recombination type, which is the same as previously reported from other vivax malaria endemic regions around the world. Conversely, Hap_9 was identified as a unique variant, generated via a rare recombination site which was also identified in a previous study [4].

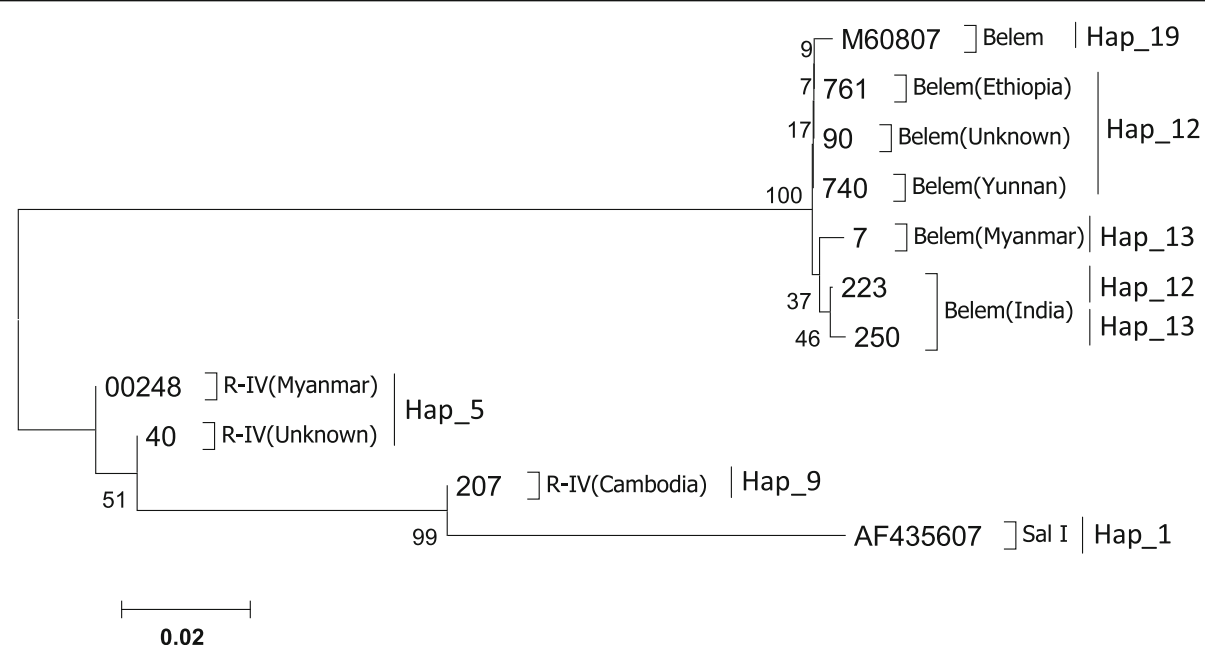

Fig. 5 Dendrogram of the PVMSP-1 icb5- 6 based on the nucleotide sequences of 6 isolates of Belem type, 3 isolates of R-IV type and Sal I reference sequence (AF435602), Belem reference sequence (M60807) 


\section{Conclusion}

In this study, the genetic diversity and phylogenetic relationship of the PvMSP-1 gene icb5-6 fragment was analyzed. Four allelic-types of $P v M S P-1$ and seventeen haplotypes were identified. Besides this, a rare recombinant site was detected in Hap_9. Based on the genetic diversity of Sal I type, a molecular barcode was proposed for preliminary tracking of $P$. vivax. The information on the genetic diversity of the PvMSP-1 icb5-6 fragment presented in this study provides positive evidence for genetic recombination in $P$. vivax populations and a basis for the correct classification and tracking of P. vivax cases.

\section{Additional files}

Additional file 1: Multilingual abstracts in the five official working languages of the United Nations. (PDF $1068 \mathrm{~kb}$ )

Additional file 2: The primers for nested PCR detection of Plasmodium spp. and PVMSP-1. (DOCX $14 \mathrm{~kb}$ )

\section{Abbreviations}

${ }^{\circ} \mathrm{C}$ : Celsius; icb: Inter-species conserved fragment; min: Minute; ml: Milliliter; No.: Number:; $P$. vivax:: Plasmodium vivax; PVMSP-1: $P$. vivax merozoite surface protein-1; Q: Glutamine; R-III: Recombination III; R-IV: Recombination IV; Salvador: Sall; SNP: Single nucleotide polymorphism; $\mu$ l: Microliter; $\mathrm{M}$ : Micromolar

\section{Acknowledgements}

The researchers would like to thank Professor Ming-bo Yin and Dr Hong-yan Li, FuDan University, for the help of data analysis and software application.

\section{Funding}

This research was supported by the Medical Science and Technique Project of Zhejiang Province (No.2013KYA041, No.2014KYB324).

\section{Availability of data and materials}

The data underlying the finding are fully available on reasonable request. Such request should be directed to the first author or the corresponding author.

\section{Authors' contributions}

RW designed the study and drafted the manuscript. ZLL carried out the study and participated in drafting the manuscript. FY and ZX collected the data materials and performed some statistical analysis. CHL and LQY participated in lab work. YLN participated in study design and coordination. HW participated in technological guidance and helped to draft the manuscript. All authors read and approved the final manuscript.

\section{Competing interests}

The authors declare that they have no competing interests.

\section{Consent for publication}

Not applicable.

\section{Ethics approval and consent to participate}

This study was approved by the Ethics Committee of Zhejiang Provincial Center for Disease Control and Prevention (Zhejiang CDC).
Received: 11 August 2016 Accepted: 12 April 2017

Published online: 05 June 2017

\section{References}

1. WHO: World Malaria Report 2013. Geneva: World Health Organization; 2013. http://www.who.int/malaria/publications/world_malaria_report_2013/report/ en/.

2. Daniels R, Volkman SK, Milner DA, Mahesh N, Neafsey DE, Park DJ, Rosen D, Angelino E, Sabeti PC, Wirth DF, Wiegand RC. A general SNP-based molecular barcode for Plasmodium falciparum identification and tracking. Malar J. 2008:7:223.

3. Schoepflin S, Valsangiacomo F, Lin E, Kiniboro B, Mueller I, Felger I. Comparison of Plasmodium falciparum allelic frequency distribution in different endemic settings by high-resolution genotyping. Malar J. 2009:8:250.

4. Zakeri S, Raeisi A, Afsharpad M, Kakar Q, Ghasemi F, Atta H, Zamani G, Memon MS, Salehi M, Djadid ND. Molecular characterization of Plasmodium vivax clinical isolates in Pakistan and Iran using pvmsp-1, pvmsp-3alpha and pvcsp genes as molecular markers. Parasitol Int. 2010; 59(1):15-21.

5. Zhong D, Bonizzoni M, Zhou G, Wang G, Chen B, Vardo-Zalik A, Cui L, Yan G, Zheng B. Genetic diversity of Plasmodium vivax malaria in China and Myanmar. Infect Genet Evol. 2011;11(6):1419-25.

6. Li YC, Wang GZ, Meng F, Zeng W, He CH, Hu XM, Wang SQ. Genetic diversity of Plasmodium vivax population before elimination of malaria in Hainan Province. China Malar J. 2015;14:78.

7. Maneerattanasak S, Gosi P, Krudsood S, Tongshoob J, Lanteri CA, Snounou G, Khusmith S. Genetic diversity among Plasmodium vivax isolates along the ThaiMyanmar border of Thailand. Malar J. 2016;15:75.

8. del Portillo HA, Longacre S, Khouri E, David PH. Primary structure of the merozoite surface antigen 1 of Plasmodium vivax reveals sequences conserved between different Plasmodium species. Proc Natl Acad Sci U S A. 1991;88(9):4030-4.

9. Putaporntip C, Jongwutiwes S, Sakihama N, Ferreira MU, Kho WG, Kaneko A Kanbara H, Hattori T, Tanabe K. Mosaic organization and heterogeneity in frequency of allelic recombination of the Plasmodium vivax merozoite surface protein-1 locus. Proc Natl Acad Sci U S A. 2002;99(25):16348-53.

10. Putaporntip C, Jongwutiwes S, Tanabe K, Thaithong S. Interallelic recombination in the merozoite surface protein 1 (MSP-1) gene of Plasmodium vivax from Thai isolates. Mol Biochem Parasitol. 1997:84(1):49-56.

11. Leclerc MC, Gauthier C, Villegas L, Urdaneta L. Genetic diversity of merozoite surface protein-1 gene of Plasmodium vivax isolates in mining villages of Venezuela (Bolivar State). Acta Trop. 2005;95(1):26-32.

12. Maestre A, Sunil S, Ahmad G, Mohmmed A, Echeverri M, Corredor M, Blair S, Chauhan VS, Malhotra P. Inter-allelic recombination in the Plasmodium vivax merozoite surface protein 1 gene among Indian and Colombian isolates. Malar J. 2004;3:4

13. Zakeri S, Mehrizi AA, Mamaghani S, Noorizadeh S, Snounou G, Djadid ND. Population structure analysis of Plasmodium vivax in areas of iran with different malaria endemicity. Am J Trop Med Hyg. 2006;74(3):394-400.

14. Premawansa S, Snewin VA, Khouri E, Mendis KN, David PH. Plasmodium vivax: recombination between potential allelic types of the merozoite surface protein MSP1 in parasites isolated from patients. Exp Parasitol. 1993; 76(2):192-9

15. Kolakovich KA, Ssengoba A, Wojcik K, Tsuboi T, al-Yaman F, Alpers M, Adams $J$ H. Plasmodium vivax: favored gene frequencies of the merozoite surface protein-1 and the multiplicity of infection in a malaria endemic region. Exp Parasitol. 1996;83(1):11-9.

16. Craig AA, Kain KC. Molecular analysis of strains of Plasmodium vivax from paired primary and relapse infections. J Infect Dis. 1996;174(2):373-9.

17. Tanabe K, Escalante A, Sakihama N, Honda M, Arisue N, Horii T, Culleton R, Hayakawa T, Hashimoto T, Longacre S, Pathirana S, Handunnetti S, Kishino $\mathrm{H}$. Recent independent evolution of mspl polymorphism in Plasmodium vivax and related simian malaria parasites. Mol Biochem Parasitol. 2007; 156(1):74-9

18. Huang B, Huang S, Su XZ, Guo H, Xu Y, Xu F, Hu X, Yang Y, Wang S, Lu F. Genetic diversity of Plasmodium vivax population in Anhui province of China. Malar J. 2014:13:13.

19. World Health Organization. Basic malaria microscopy Part I: Learner's guide.2010.

20. Snounou G, Viriyakosol S, Zhu XP, Jarra W, Pinheiro L. V.E. do Rosario, S. Thaithong, and K.N. Brown. High sensitivity of detection of human malaria 
parasites by the use of nested polymerase chain reaction. Mol Biochem Parasitol. 1993;61(2):315-20.

21. Singh B, Bobogare A, Cox-Singh J, Snounou G, Abdullah MS, Rahman HA. A genus- and species-specific nested polymerase chain reaction malaria detection assay for epidemiologic studies. Am J Trop Med Hyg. 1999;60(4): 687-92.

22. Zhang $S \mathrm{y}$, L.H.m, Xu L s, Gao Q, Shen Y z. Polymorphism analysis of Plasmodium vivax merozoite surface protein1 (PvMsp-1) gene from different malaria endemic area of China. Chinese Journal of Zoonoses. 2004;20(1):26-9.

23. Tamura K, Stecher G, Peterson D, Filipski A, Kumar S. MEGA6: Molecular Evolutionary Genetics Analysis version 6.0.. Mol Biol Evol. 2013;30(12):2725-9.

24. Librado P, Rozas J. DnaSP v5: a software for comprehensive analysis of DNA polymorphism data. Bioinformatics. 2009:25(11):1451-2

25. Pindolia DK, Garcia AJ, Huang Z, Smith DL, Alegana VA, Noor AM, Snow RW, Tatem AJ. The demographics of human and malaria movement and migration patterns in East Africa. Malar J. 2013;12:397.

26. Moon SU, Lee HW, Kim JY, Na BK, Cho SH, Lin K, Sohn WM, Kim TS. High frequency of genetic diversity of Plasmodium vivax field isolates in Myanmar. Acta Trop. 2009;109(1):30-6.

27. Gutierrez A, Vicini J, Patarroyo ME, Murillo LA, Patarroyo MA. Plasmodium vivax: polymorphism in the merozoite surface protein 1 gene from wild Colombian isolates. Exp Parasitol. 2000;95(3):215-9.

28. Joy DA, Gonzalez-Ceron L, Carlton JM, Gueye A, Fay M, McCutchan TF, Su XZ. Local adaptation and vector-mediated population structure in Plasmodium vivax malaria. Mol Biol Evol. 2008;25(6):1245-52.

29. Cerritos R, Gonzalez-Ceron L, Nettel JA, Wegier A. Genetic structure of Plasmodium vivax using the merozoite surface protein 1 icb5-6 fragment reveals new hybrid haplotypes in southern Mexico. Malar J. 2014;13:35.

\section{Submit your next manuscript to BioMed Central and we will help you at every step:}

- We accept pre-submission inquiries

- Our selector tool helps you to find the most relevant journal

- We provide round the clock customer support

- Convenient online submission

- Thorough peer review

- Inclusion in PubMed and all major indexing services

- Maximum visibility for your research

Submit your manuscript at www.biomedcentral.com/submit 